\title{
BMJ Global Health Where there is no local author: a network bibliometric analysis of authorship parasitism among research conducted in sub-Saharan Africa
}

\author{
Chris A Rees, ${ }^{1,2}$ Mohsin Ali, ${ }^{3}$ Rodrick Kisenge, ${ }^{4}$ Readon C Ideh, ${ }^{5}$ \\ Stephanie J Sirna, ${ }^{6}$ Carl D Britto, ${ }^{7}$ Peter N Kazembe, ${ }^{8}$ Michelle Niescierenko, ${ }^{9,10}$ \\ Christopher P Duggan, ${ }^{11,12}$ Karim P Manji
}

\begin{abstract}
To cite: Rees CA, Ali M, Kisenge $\mathrm{R}$, et al. Where there is no local author: a network bibliometric analysis of authorship parasitism among research conducted in sub-Saharan Africa. BMJ Global Health 2021;6:e006982. doi:10.1136/ bmjgh-2021-006982
\end{abstract}

Handling editor Seye Abimbola

PNK deceased

CAR and MA contributed equally.

CPD and KPM are joint senior authors.

Received 22 July 2021 Accepted 25 September 2021

Check for updates

C Author(s) (or their employer(s)) 2021. Re-use permitted under CC BY-NC. No commercial re-use. See rights and permissions. Published by BMJ.

For numbered affiliations see end of article.

Correspondence to Dr Chris A Rees; chris.rees@emory.edu

\section{ABSTRACT}

Introduction Authorship parasitism (ie, no authors affiliated with the country in which the study took place) occurs frequently in research conducted in lowincome and middle-income countries, despite published recommendations defining authorship criteria. The objective was to compare characteristics of articles exhibiting authorship parasitism in sub-Saharan Africa to articles with author representation from sub-Saharan African countries.

Methods A bibliometric review of articles indexed in PubMed published from January 2014 through December 2018 reporting research conducted in sub-Saharan Africa was performed. Author affiliations were assigned to countries based on regular expression algorithms. Choropleth maps and network diagrams were created to determine where authorship parasitism occurred, and multivariable logistic regression was used to determine associated factors.

Results Of 32061 articles, $14.8 \%(n=4754)$ demonstrated authorship parasitism, which was most common among studies from Somalia $(n=175 / 233$, $75.1 \%)$ and Sao Tome and Principe $(n=20 / 28,71.4 \%)$. Authors affiliated with USA and UK institutions were most commonly involved in articles exhibiting authorship parasitism. Authorship parasitism was more common in articles: published in North American journals (adjusted OR (aOR) 1.26, 95\% Cl 1.07 to 1.50) than in sub-Saharan African journals, reporting work from multiple subSaharan African countries (aOR 8.41, 95\% Cl 7.30 to 9.68) compared with work from upper-middle income subSaharan African countries, with $<5$ authors (aOR 14.46, $95 \% \mathrm{Cl} 12.81$ to 16.35 ) than $>10$ authors, and was less common in articles published in French (aOR $0.60,95 \% \mathrm{Cl}$ 0.41 to 0.85 ) than English.

Conclusions Authorship parasitism was common in articles reporting research conducted in sub-Saharan Africa. There were reliable predictors of authorship parasitism. Investigators and institutions in high-income countries, as well as funding agencies and journals should promote research from sub-Saharan Africa, including its publication, in a collaborative and equitable manner.

\section{Key questions}

What is already known?

- Research conducted in low-income and middleincome countries (LMICs) often involves collaboration between researchers from LMICs and high-income countries (HICs)

- Imbalances in power, spoken languages, opportunities for funding, academic and research priorities between LMIC and HIC investigators can make the benefits of such collaboration unequal, with HIC investigators traditionally benefitting more.

- Despite multiple calls to 'decolonise global health' prior studies indicate that authorship parasitism, defined as articles with 'no listed authors from the LMIC in which a study is conducted', occurs in as much as $13 \%$ of articles reporting on research conducted in the African continent and that investigators from the USA, UK and Canada are commonly involved in such articles.

\section{INTRODUCTION}

Research conducted in low-income and middle-income countries (LMICs) often involves collaboration between researchers from LMICs and high-income countries (HICs). ${ }^{1}$ However, imbalances in power, spoken languages, opportunities for funding, academic and research priorities can make the benefits of such collaboration unequal, with HIC investigators traditionally benefitting more. ${ }^{23}$

One example of imbalanced benefits in global health research is authorship in peerreviewed, original research articles. Previous studies from biomedical disciplines such as epidemiology, orthopaedics, palliative care, maternal health and paediatrics suggest that HIC authors often occupy the most prominent authorship positions-ie, first and last-in articles reporting research conducted in LMICs. ${ }^{4-8}$ 


\section{Key questions}

\section{What are the new findings?}

- In a bibliometric review of 32061 articles reporting original research performed in sub-Saharan Africa published from 2014 through 2018, 14.8\% ( $n=4754)$ met the definition of authorship parasitism.

- Authorship parasitism was most common among research conducted in Somalia and Sao Tome and Principe.

- Articles demonstrating authorship parasitism were more likely to be published in journals based outside of sub-Saharan Africa, conducted in lower-middle income sub-Saharan African countries, lowincome sub-Saharan African countries and multiple sub-Saharan African countries.

\section{What do the new findings imply?}

- Though imbalances in authorship in research conducted in subSaharan Africa is but one part of larger problems in inequities in academic global health, it is certainly a manifestation.

- Understanding the locations, contributing investigators' location and factors associated with authorship parasitism will help inform policies and interventions to reduce this extractive practice in the future.

- Investigators working in sub-Saharan Africa should perform research, including its publication, in a collaborative and equitable manner.

These, and other studies, suggest such authorship inequities may be more pronounced in sub-Saharan Africa. ${ }^{9}$

Despite multiple calls to 'decolonise global health', to build research capacity in LMICs, and to avoid exploitative research practices in LMICs, ${ }^{10-13}$ prior studies indicate that authorship parasitism, defined as articles with 'no listed authors from the LMIC in which a study is conducted', occurs in as much as $4 \%-13 \%$ of articles reporting research conducted in the African continent. ${ }^{814}$ Authorship parasitism can damage partnerships between LMIC and HIC investigators while also perpetuating gaps in power and influence. ${ }^{15}$ Moreover, publishing papers without full representation of the personnel who meet authorship criteria is against the recommendation of the International Committee of Medical Journal Editors (ICMJE). ${ }^{16}$ Prior studies suggest that authorship parasitism is common when investigators from the USA, UK and Canada are involved and that 'neo-colonial science' may be to blame for such inequitable practices. ${ }^{14}{ }^{17}$ However, these studies have not elucidated whether other factors, such as journal region, article language, funding source and number of authors are associated with authorship parasitism. Understanding such factors is needed to identify, and thereby eliminate, this extractive practice. Our objective was to determine the prevalence, location, contributing investigators and factors associated with authorship parasitism among articles reporting research conducted in sub-Saharan Africa.

\section{METHODS}

\section{Study design}

We conducted a bibliometric review and analysis of authorship parasitism among articles indexed in PubMed reporting original research performed in sub-Saharan Africa and published from 2014 through 2018. The list of sub-Saharan African countries was defined based on the World Bank region classification. ${ }^{18}$ This study period was selected because the National Center for Biotechnology Information (NCBI) began indexing author affiliations in PubMed starting $2014^{19}$ and we aimed to encompass a 5 -year period. We combined human review with a custom natural-language-processing algorithm to assign study country(ies) for each paper, and author affiliation(s) for each author in each article. Articles with authorship parasitism were defined as those in which none of the listed authors were affiliated with the sub-Saharan African country(ies) in which those studies were conducted. ${ }^{8}$

\section{Patient and public involvement statement}

The development of the research question was informed by observed imbalances in research collaboration in subSaharan Africa. Patients were not involved in the design, recruitment or conduct of the study, nor were they advisers in this study. Results of this study will be made publicly available through publication.

\section{Query design and eligibility criteria}

To retrieve articles reporting original research conducted in sub-Saharan Africa, we used the names of the 49 subSaharan African countries to query PubMed for articles published from 1 January 2014 through 31 December 2018. We performed the search on 1 August 2019. We used each country name to query each article's title, abstract, keywords and Medical Subject Heading (MeSH) fields (online supplemental file 1). Articles published in all languages were included since the NCBI catalogues articles in other languages but indexes in English. Articles reporting research conducted in more than one subSaharan African country were included.

The query was devised iteratively. In each iteration, two reviewers independently reviewed a $10 \%$ random sample of titles and abstracts. In so doing, we revised our query in two ways. First, we added Boolean 'NOT' operators to exclude non-specific articles. Representative examples include 'guinea pig' (to distinguish from the country Guinea) and 'Aspergillus niger' (to distinguish from Niger). Second, we added terms to exclude articles based on publication type suggesting non-original research (eg, editorials, reviews, case reports, commentaries, viewpoints, letters to the editor). Supplemental articles were also excluded as they contained requested articles, policy statements, and conference abstracts.

After running our devised query, we excluded articles (1) without listed authors, (2) without author affiliation data (provided there was no group author) and (3) articles where only the first author had affiliation data (provided that the affiliation field likely did not contain data for all authors). For this last condition, we used a set of 'regular expressions' - a pattern-matching method for text-to query for patterns that could indicate the paper had information on multiple authors' affiliations. Such 
patterns include semicolons (often used as a delimiter between multiple affiliations), use of special symbols (eg, $\dagger, \$, \S)$, or use of English honorifics (eg, Dr, Ms, Mr). Regular expressions are akin to a keyword search but can incorporate advanced logic (eg, distinguishing nested country names such as 'Guinea' vs 'Equatorial Guinea', 'Guinea-Bissau', or 'Papua New Guinea'). Finally, we excluded Global Burden of Disease studies as these represent analyses of available data sets and are unlikely to represent original research done in sub-Saharan Africa; these studies were excluded based on the group author name listed.

\section{Algorithm design, application and validation}

We designed two natural-language-processing algorithms to assign study country(ies) and author affiliation country(ies) to all articles meeting inclusion criteria. Each algorithm relied on 'regular expressions'. Both classification algorithms primarily applied a dictionary of regular expressions to the relevant subset(s) of the textual metadata. Specifically, to assign study country(ies), we searched the article title, keywords, MeSH terms and a subset of the abstract likely to contain the study country (ie, the last sentence of introduction, methods or results). To assign author affiliation country(ies), we searched each author's affiliation field(s). Both algorithms allowed for multiple matches. The study country algorithm was restricted to the 49 sub-Saharan African countries, whereas the author affiliation country algorithm searched for 186 countries, according to the World Bank classification. ${ }^{17}$ To validate these algorithms, we randomly sampled and manually reviewed 5\% of articles ( $\mathrm{n}=1323$, with 9044 authors $)$ and compared the diagnostic performance of each algorithm compared with gold standard of manual review.

We designated the following set of article characteristics as high risk for algorithmic misassignment and manually reviewed them: (1) absence of abstract, (2) single author, (3) presence of group author and (4) presence of the same number of affiliation fields for all authors (potentially indicating that all authors' affiliations were reported in the same field). For articles with sole group authorship and no listed authors in PubMed, we reviewed the full text to assign author affiliations.

\section{Variables and other data sources}

We extracted the following variables from PubMed for articles meeting inclusion criteria: PubMed identification number, article title, abstract, number of authors, author name(s), author affiliation(s), year and month of publication, journal name, journal volume, MeSH terms and listed funding. We assigned each journal a World Bank region based on where the journal is published as reported in the Web of Science Journal Citation Report. Author country affiliations were categorised as lowincome, lower-middle income, upper-middle-income and high-income using the World Bank country designations contemporaneous with the year of the article's publication. $^{18}$

\section{Statistical analyses}

We determined the prevalence of authorship parasitism over the study period and created a choropleth map to visualise the relative frequency of articles with authorship parasitism among sub-Saharan African countries. We calculated the error rate of our query against results from manual review of study country and author affiliation assignment.

For each pairwise relationship (ie, between a subSaharan African country and foreign country author affiliation), we calculated the odds of authorship parasitism when 'exposed' to at least one author with that foreign affiliation, provided there were at least 10 articles with that pairwise relationship (eg, at least 10 articles with at least one author affiliated with the USA for articles reporting research conducted in Tanzania).

To analyse bivariate trends in authorship parasitism, we created a network diagram to demonstrate the relative frequency of the relationship between authorship parasitism among countries in sub-Saharan Africa. Following the estimation of the number of parasitic articles stratified by country, a pair-wise parasitism index was calculated for countries. This was done by dividing the number of articles in each pairwise combination by the highest number in any pain-wise combination (548 for the Kenya-US combination). Each pairwise combination thus received a value between 0 and 1 , with values closer to 0 representing low authorship parasitism and numbers at the opposite end of the spectrum representing high authorship parasitism. Countries comprising the rows and columns were arranged based on the patterns of parasitism, using the complexheatmap package in $\mathrm{R}(\mathrm{R}$ Foundation for Statistical Computing, Vienna, Austria) to derive pairwise distances and subsequent pairwise distance trees.

We used univariable and multivariable logistic regression to determine factors associated with authorship parasitism compared with articles with author representation from the country where the study was conducted. The candidate variables included in our multivariable logistic regression model were selected $a$ priori based on prior work suggesting power dynamics contributing to inequities in publication of work conducted in LMICs at the journal level ${ }^{20}{ }^{21}$ and prior work suggesting that authorship parasitism is more common in low-income countries and among those conducted in multiple LMICs. ${ }^{8}$ Funding and the number of authors included were selected as candidate variables to assess this potential association as well. Candidate variables in which the $\mathrm{p}$ value was $<0.2$ in the univariable model were included in the multivariable model. All analyses were conducted using R V.4.0.3 (R Foundation for Statistical Computing).

\section{RESULTS}

There were 38536 articles identified through our initial query, $83.2 \%$ ( $\mathrm{n}=32061$ ) met inclusion criteria (figure 1 ). Of the 32061 articles meeting our inclusion criteria, 


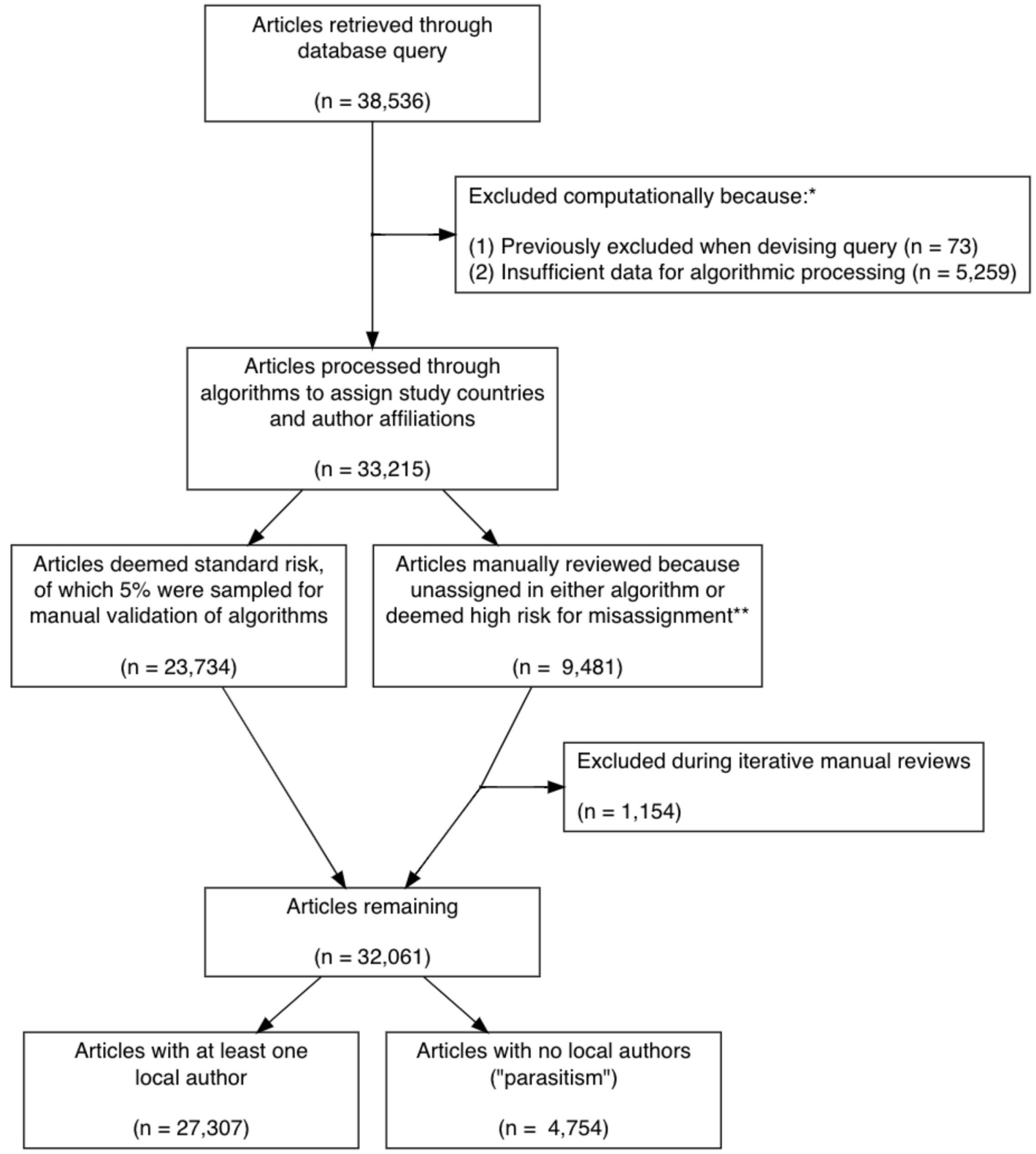

Figure 1 Selection of articles included in the analysis. *Eleven articles were previously excluded when devising query and had insufficient data for algorithmic processing. ${ }^{* *}$ The following set of article characteristics as high risk for algorithmic misassignment and were manually reviewed: (1) absence of abstract, (2) single author, (3) presence of group author and (4) presence of the same number of affiliation fields for all authors (potentially indicating that all authors' affiliations were reported in the same field).

$14.8 \%(\mathrm{n}=4754)$ met the definition of authorship parasitism. The remaining $85.2 \%(\mathrm{n}=27319)$ had at least one author with an affiliation in the same sub-Saharan African country where the study was conducted. Characteristics of included articles are summarised in table 1. Our study country and author affiliation algorithms both demonstrated high global sensitivity and specificity (ie, $>99 \%$ ) in assigning study country and author affiliation country(ies) when compared with manual review as a reference standard. The annual frequency of authorship parasitism did not change appreciably during the study period (figure 2).
A significant proportion of articles also had few authors affiliated with the study country, regardless of the number of authors. Of 16187 articles with 5-10 authors, local authors comprised $\leq 25 \%$ of authors in 4999 (30.9\%) articles. Of 3901 articles with 11-15 authors, local authors comprised $\leq 25 \%$ of authors in 1115 (28.6\%) articles. In 940 articles with 16-20 authors, local authors comprised $\leq 25 \%$ of authors in $349(37.1 \%)$ articles. And in 560 articles with $>20$ authors, local authors comprised $\leq 25 \%$ of authors in $231(41.2 \%)$ articles.

There were 228829 authors in the published articles included in our analysis. Of authors with assigned 
Table 1 Characteristics of articles reporting research conducted in sub-Saharan Africa, 2014-2018

\begin{tabular}{|c|c|}
\hline & n (\%) \\
\hline \multicolumn{2}{|l|}{ Journal publisher region } \\
\hline Sub-Saharan Africa & $2940(9.2)$ \\
\hline East Asia and Pacific & $267(0.8)$ \\
\hline Europe and Central Asia & $17133(53.4)$ \\
\hline Latin America and the Caribbean & $53(0.2)$ \\
\hline Middle East and North Africa & $159(0.5)$ \\
\hline North America & $11094(34.6)$ \\
\hline South Asia & $427(1.3)$ \\
\hline \multicolumn{2}{|l|}{ Language of article } \\
\hline English & $31262(97.5)$ \\
\hline French & $742(2.3)$ \\
\hline Other languages or multiple languages* & $69(0.2)$ \\
\hline \multicolumn{2}{|l|}{ Study country income group } \\
\hline Low-income & $5697(17.8)$ \\
\hline Lower-middle income & $13906(43.4)$ \\
\hline $\begin{array}{l}\text { Upper-middle income and high } \\
\text { income } †\end{array}$ & $9890(30.9)$ \\
\hline Multicountry study & $2550(8.0)$ \\
\hline \multicolumn{2}{|l|}{ Funding agency type } \\
\hline US government & $23015(71.8)$ \\
\hline Non-US government & $1019(3.2)$ \\
\hline Private foundation & $440(1.4)$ \\
\hline Other & $687(2.1)$ \\
\hline Multiple types & $1823(5.7)$ \\
\hline None listed & $5089(15.9)$ \\
\hline Number of authors, median (IQR) & $6(4-9)$ \\
\hline Group authorship included & $1037(3.2)$ \\
\hline
\end{tabular}

*Other includes Chinese $(n=26)$, German $(n=39)$, and Dutch $(n=4)$.

†Includes two high-income countries in sub-Saharan Africa (ie, Equatorial Guinea and Seychelles).

country affiliations, $89478(39.1 \%)$ were affiliated with HICs, 25073 (11.0\%) were affiliated with upper-middle income countries, $34565(15.1 \%)$ were affiliated with lower-middle income countries, 55503 (24.2\%) were affiliated with low-income countries and 24210 (10.6\%) were affiliated with an HIC and a combination of income classifications.

Authorship parasitism occurred most commonly in published articles reporting research conducted in Somalia $(\mathrm{n}=175 / 233,75.1 \%)$, Sao Tome and Principe $(\mathrm{n}=20 / 28,71.4 \%)$, Comoros $(\mathrm{n}=30 / 46,65.2 \%)$, Eritrea $(n=41 / 67,61.2 \%)$ and Cape Verde $(n=25 / 47,53.2 \%)$ (figure 3). Authorship parasitism occurred in as few as $7.3 \%(\mathrm{n}=404 / 5554)$ of articles published on research conducted in South Africa. The USA ( $\mathrm{n}=2079 / 11800$, $17.6 \%)$ and the UK $(\mathrm{n}=800 / 5611,14.3 \%)$ were the countries most consistently involved in published articles demonstrating authorship parasitism (figure 4).
Types of author relationship by publication year

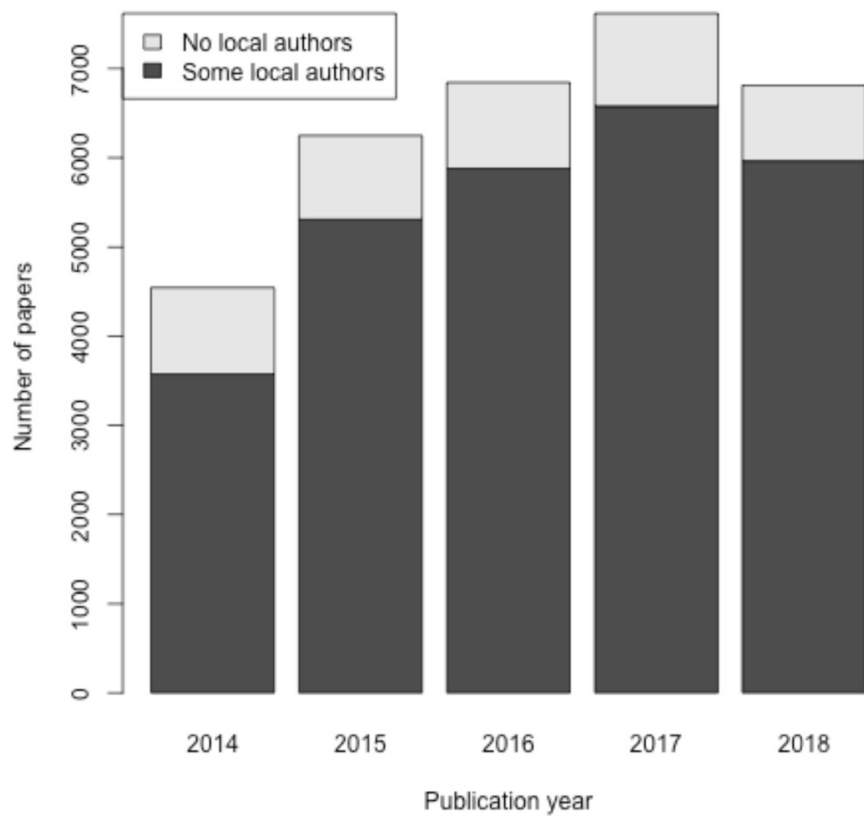

Figure 2 Prevalence of authorship parasitism in subSaharan Africa in articles published from 2014 to 2018 among 32061 articles indexed on PubMed.

Other notable authorship parasitism trends reflected the history of colonialism (eg, Angola and Portugal) and shared language (eg, Angola and Brazil). Proportionally, authorship parasitism occurred most commonly when the USA was involved in research conducted in South Africa, Kenya and Uganda. For studies in which the UK was involved, authorship parasitism was proportionally most commonly present when the study was conducted in South Africa, Kenya or Uganda. Though Canada and the Netherlands were less commonly involved in published articles demonstrating authorship parasitism, these two countries were most frequently involved in authorship parasitism in studies conducted in South Africa and Kenya, by proportion of articles. In pairwise comparisons, the relative odds of authorship parasitism by each

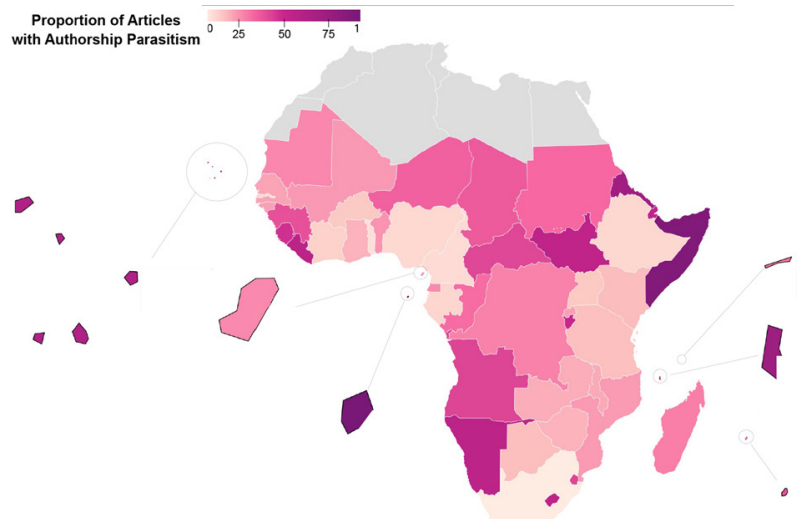

Figure 3 Choropleth of proportion of papers indexed on PubMed without any local authors (authorship parasitism) for original research done in sub-Saharan Africa, 2014-2018. 


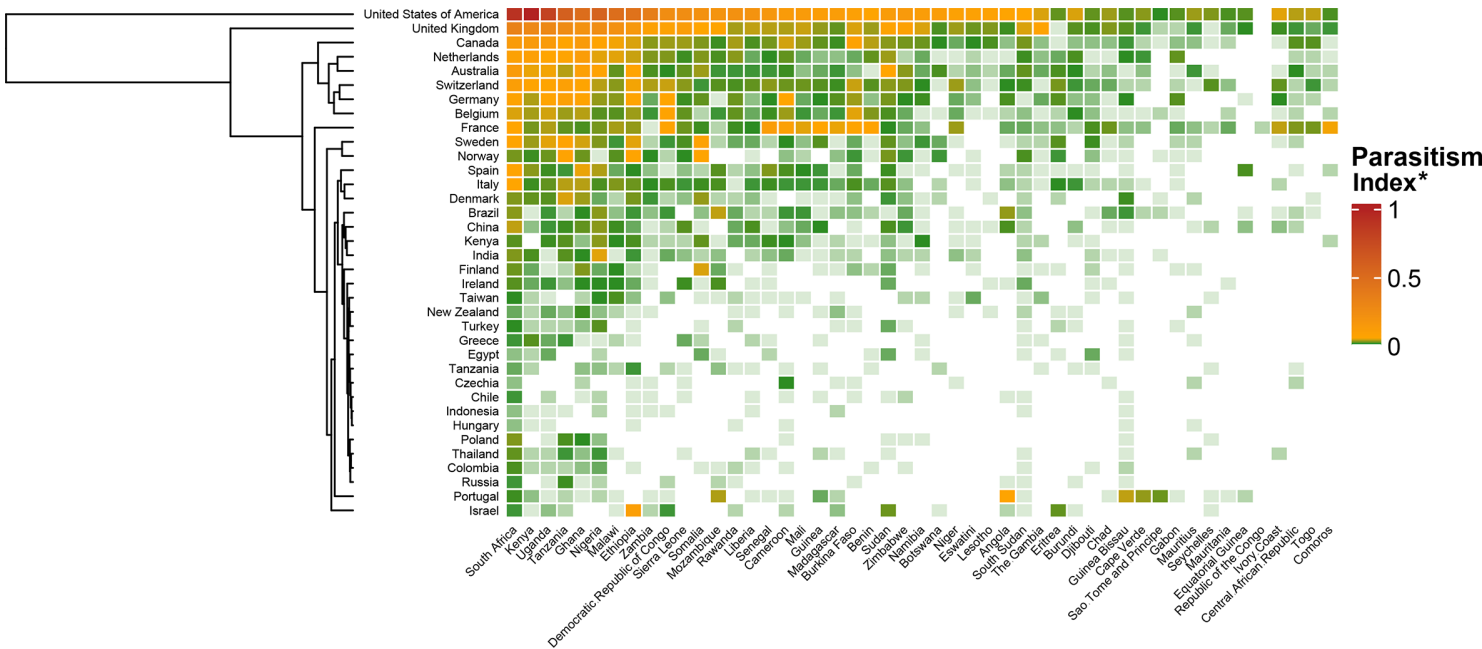

Figure 4 Network diagram of relationships between sub-Saharan African countries and foreign authors' country affiliations among papers without any local authors. *Parasitism index calculated by dividing the number of articles in each pairwise combination by the highest number in any pain-wise combination, which was 548 in the US-Kenya combination. Each pairwise combination thus received a value between 0 and 1, values closer to 0 represented low parasitism and numbers at the opposite end of the spectrum represented high parasitism.

foreign country varied per sub-Saharan African country (online supplemental table 1). However, the presence of authors from the USA, UK and Canada remained commonly associated with authorship parasitism in these pairwise comparisons.

On multivariable regression, articles demonstrating authorship parasitism were more likely to be published in journals based in Latin America and the Caribbean (adjusted OR (aOR) 2.78, 95\% CI 1.13 to 6.39), North America (aOR 1.26, 95\% CI 1.07 to 1.50 ), Europe and Central Asia (aOR 1.42, 95\% CI 1.22 to 1.68 ) and East Asia and Pacific (aOR 1.84, 95\% CI 1.24 to 2.71) compared with journals based in sub-Saharan Africa (table 2). Articles published in French were less likely to have authorship parasitism (aOR 0.60, 95\% CI 0.41 to 0.85 ) than articles published in English. In contrast, articles published in languages other than English or French, or multiple languages had over ninefold greater odds of demonstrating authorship parasitism (aOR 9.40, $95 \%$ CI 4.86 to 18.78 ) when compared with articles published in English. Compared with articles reporting work conducted in upper-middle income countries in sub-Saharan Africa, articles reporting research conducted in lower-middle income sub-Saharan African countries (aOR 2.05, 95\% CI 1.83 to 2.30), low-income sub-Saharan African countries (aOR 1.76, 95\% CI 1.57 to 1.99) and multiple sub-Saharan African countries (aOR 8.41, 95\% CI 7.30 to 9.68 ) were more likely to exhibit authorship parasitism (table 2).

Articles reporting funding from the US government were modestly less likely to have parasitic authorship bylines (aOR $0.79,95 \%$ CI 0.63 to 0.98 ) than articles with no listed funding source (table 2). Articles reporting funding from multiple sources were less likely to demonstrate authorship parasitism when compared with articles with no funding source listed (aOR 0.86, 95\% CI 0.77 to 0.96$)$. The number of authors was associated with authorship parasitism among articles reporting research conducted in sub-Saharan Africa. Articles with $<5$ authors (aOR 14.46, 95\% CI 12.81 to 16.35 ) and articles with 5-10 authors (aOR 2.80, 95\% CI 2.50 to 3.15 ) were more likely to show authorship parasitism than articles with $>10$ authors. The presence of a group author was not associated with authorship parasitism among articles reporting research conducted in sub-Saharan Africa (aOR 1.09, $95 \%$ CI 0.88 to 1.34 ).

The covariate most highly and consistently associated with authorship parasitism was the presence of a highincome author, particularly those from the USA (aOR $13.02,95 \%$ CI 10.77 to 15.72 ), the UK (aOR $10.28,95 \%$ CI 9.06 to 11.68 ) and both the USA and the UK (aOR $12.88,95 \%$ CI 11.33 to 14.67 ).

\section{DISCUSSION}

In our analysis of over 32000 published articles reporting research conducted in sub-Saharan Africa, approximately one in seven published articles did not include any authors from the country where the study was conducted, and many articles included only a moderate proportion of authors from the study country. Several HICs were commonly involved in articles demonstrating authorship parasitism. Authorship parasitism occurred more commonly in studies conducted in multiple subSaharan African countries and in low-income countries than in upper-middle-income sub-Saharan African countries. Though imbalance in authorship in research conducted in sub-Saharan Africa is but 'the tip of the iceberg' in inequities in academic global health, ${ }^{22} 23$ it is certainly a manifestation. Understanding the countries, contributing investigators' countries and associated 
Table 2 Logistic regression of article-level factors associated with authorship parasitism

\begin{tabular}{|c|c|c|c|c|c|c|}
\hline & $\begin{array}{l}\text { Article with any } \\
\text { local authors, } \\
\text { n (\%) }\end{array}$ & $\begin{array}{l}\text { Article without } \\
\text { local authors, } \\
\text { n (\%) }\end{array}$ & $\begin{array}{l}\text { OR } \\
(95 \% \mathrm{Cl})\end{array}$ & $P$ value & Adjusted OR $(95 \% \mathrm{Cl})^{*}$ & $P$ value \\
\hline \multicolumn{7}{|l|}{ Journal publisher region } \\
\hline Sub-Saharan Africa & $2719(10.0)$ & $220(4.6)$ & Referent & & Referent & \\
\hline $\begin{array}{l}\text { East Asia and } \\
\text { Pacific }\end{array}$ & $219(0.8)$ & $48(1.1)$ & 2.71 (1.91 to 3.78$)$ & $<0.001$ & 1.84 (1.24 to 2.71$)$ & 0.002 \\
\hline $\begin{array}{l}\text { Europe and Central } \\
\text { Asia }\end{array}$ & $14333(52.5)$ & $2792(58.7)$ & 2.41 (2.09 to 2.78 ) & $<0.001$ & 1.43 (1.22 to 1.68$)$ & $<0.001$ \\
\hline $\begin{array}{l}\text { Latin America and } \\
\text { the Caribbean }\end{array}$ & $37(0.1)$ & $16(0.3)$ & 5.34 (2.85 to 9.59$)$ & $<0.001$ & 2.78 (1.13 to 6.39$)$ & 0.020 \\
\hline $\begin{array}{l}\text { Middle East and } \\
\text { North Africa }\end{array}$ & $137(0.5)$ & $22(0.4)$ & 1.98 (1.21 to 3.11$)$ & $<0.001$ & 1.03 (0.58 to 1.75$)$ & 0.913 \\
\hline North America & $9462(34.7)$ & 1629 (34.3) & 2.13 (1.84 to 2.47$)$ & $<0.001$ & 1.26 (1.07 to 1.50$)$ & 0.006 \\
\hline South Asia & $400(1.4)$ & $27(0.6)$ & 0.83 (0.54 to 1.23$)$ & 0.389 & 0.84 (0.52 to 1.30$)$ & 0.450 \\
\hline \multicolumn{7}{|l|}{ Language of article } \\
\hline English & 26577 (97.3) & 4675 (98.3) & Referent & & Referent & \\
\hline French & $703(2.5)$ & $37(0.8)$ & $0.29(0.21$ to 0.41$)$ & $<0.001$ & $0.60(0.41$ to 0.85$)$ & 0.006 \\
\hline $\begin{array}{l}\text { Other languages or } \\
\text { multiple languages }\end{array}$ & $27(0.2)$ & $42(0.9)$ & $8.84(5.41$ to 14.51$)$ & $<0.001$ & 9.40 (4.86 to 18.78$)$ & $<0.001$ \\
\hline \multicolumn{7}{|c|}{ Study country income group } \\
\hline $\begin{array}{l}\text { Upper-middle } \\
\text { income† }\end{array}$ & $5213(19.1)$ & $484(10.2)$ & Referent & & Referent & \\
\hline $\begin{array}{l}\text { Lower-middle } \\
\text { income }\end{array}$ & $11822(43.3)$ & $2084(43.9)$ & 1.90 (1.71 to 2.11$)$ & $<0.001$ & 2.05 (1.83 to 2.30$)$ & $<0.001$ \\
\hline Low-income & $8653(31.7)$ & $1237(26.0)$ & 1.54 (1.38 to 1.72$)$ & $<0.001$ & 1.76 (1.57 to 1.99$)$ & $<0.001$ \\
\hline Multicountry study & $1604(5.9)$ & 946 (19.9) & 6.35 (5.62 to 7.19$)$ & $<0.001$ & 8.41 (7.30 to 9.68$)$ & $<0.001$ \\
\hline \multicolumn{7}{|l|}{ Funding agency type } \\
\hline US government & $4384(16.1)$ & $704(14.8)$ & 0.86 (0.79 to 0.94$)$ & $<0.001$ & 0.79 (0.63 to 0.98$)$ & 0.033 \\
\hline $\begin{array}{l}\text { Non-US } \\
\text { government }\end{array}$ & $354(1.3)$ & $86(1.8)$ & 1.31 (1.02 to 1.65$)$ & 0.002 & 0.99 (0.76 to 1.29$)$ & 0.957 \\
\hline Private foundation & $1671(6.1)$ & $148(3.1)$ & 0.48 (0.40 to 0.56$)$ & $<0.001$ & 0.84 (0.65 to 1.07$)$ & 0.161 \\
\hline Other* & $595(2.2)$ & $92(1.9)$ & 0.83 (0.66 to 1.03$)$ & 0.103 & 0.53 (0.43 to 0.64$)$ & $<0.001$ \\
\hline Multiple types & 903 (3.3) & $115(2.4)$ & 0.68 (0.56 to 0.83 ) & $<0.001$ & $0.86(0.77$ to 0.96$)$ & 0.005 \\
\hline None listed & 19400 (71.0) & 3609 (76.0) & Referent & & Referent & \\
\hline \multicolumn{7}{|l|}{ Number of authors } \\
\hline$<5$ & $7820(28.6)$ & $2614(55.0)$ & 4.64 (4.20 to 5.15$)$ & $<0.001$ & 14.46 (12.81 to 16.35$)$ & $<0.001$ \\
\hline $5-10$ & 12699 (46.5) & $1652(34.7)$ & 1.81 (1.63 to 2.01$)$ & $<0.001$ & 2.80 (2.50 to 3.15$)$ & $<0.001$ \\
\hline$>10$ & $6788(24.9)$ & $488(10.3)$ & Referent & & Referent & \\
\hline \multicolumn{7}{|l|}{ Any group author } \\
\hline No & 26409 (96.7) & 4625 (97.3) & Referent & & Referent & \\
\hline Yes & 898 (3.3) & $129(2.7)$ & 0.82 (0.67 to 0.98$)$ & 0.04 & 1.09 (0.88 to 1.34$)$ & 0.439 \\
\hline \multicolumn{7}{|c|}{ High-income country affiliated authors outside sub-Saharan Africa } \\
\hline None & $9240(33.8)$ & $404(8.5)$ & Referent & & Referent & \\
\hline $\begin{array}{l}\text { High-income } \\
\text { country (not UK or } \\
\text { USA) }\end{array}$ & $5320(19.5)$ & $1482(31.2)$ & 6.37 (5.68 to 7.16 ) & $<0.001$ & 8.16 (7.04 to 9.47$)$ & $<0.001$ \\
\hline $\begin{array}{l}\text { At least one UK } \\
\text { affiliation }\end{array}$ & $3211(11.8)$ & $604(12.7)$ & 4.30 (3.77 to 4.91$)$ & $<0.001$ & 10.28 (9.06 to 11.68$)$ & $<0.001$ \\
\hline $\begin{array}{l}\text { At least one US } \\
\text { affiliation }\end{array}$ & 8005 (29.3) & $1999(42.0)$ & 5.71 (5.11 to 6.39$)$ & $<0.001$ & 13.02 (10.77 to 15.72$)$ & $<0.001$ \\
\hline
\end{tabular}


Table 2 Continued

\begin{tabular}{lclllll}
\hline & $\begin{array}{l}\text { Article with any } \\
\text { local authors, } \\
\mathbf{n ~ ( \% )}\end{array}$ & $\begin{array}{l}\text { Article without } \\
\text { local authors, } \\
\mathbf{n ~ ( \% ) ~}\end{array}$ & $\begin{array}{l}\text { OR } \\
\mathbf{( 9 5 \% ~ C l )}\end{array}$ & P value & Adjusted OR (95\% Cl) & P value \\
\hline $\begin{array}{l}\text { At least one US } \\
\text { and UK } \\
\text { affiliations }\end{array}$ & $1531(5.6)$ & $265(5.6)$ & $3.96(3.36$ to 4.66) & $<0.001$ & $12.88(11.33$ to 14.67) \\
\hline
\end{tabular}

${ }^{*}$ Candidate variables in which the $p$ value was $<0.2$ in the univariable model were included in the multivariable model.

†Includes two high-income countries in sub-Saharan Africa (ie, Equatorial Guinea and Seychelles).

factors may help inform policies and interventions to reduce authorship parasitism in the future.

The prevalence of authorship parasitism among articles reporting research conducted in sub-Saharan Africa in our study was similar to that reported previously in work assessing authorship in sub-Saharan Africa demonstrating authorship parasitism rates of $13 \%-14 \% .^{14} 24$ Other studies assessing authorship distribution among literature specific to infectious diseases ${ }^{25}$ and paediatrics ${ }^{8}$ demonstrated much lower rates of authorship parasitism in sub-Saharan Africa. The reasons behind these differences are likely multifactorial. The fields of infectious diseases and paediatrics traditionally receive more international funding than other fields ${ }^{26}$ and long-term collaborations between LMICs and HICs are common in these fields, which may contribute to less frequent authorship parasitism due to long-standing collaborations. We were unable to evaluate if rates of authorship parasitism differed by disease studied due to our use of bibliometrics and the presence of multiple disease categories found in $\mathrm{MeSH}$ terms in our article population. Further study of authorship parasitism in different fields may be merited to identify if investigators in some fields are more culpable than others in such practices.

Authorship parasitism occurred most frequently in countries including Somalia, Sao Tome and Principe, Comoros, Eritrea and Cape Verde. These countries are all classified as low-income or lower-middle income countries. ${ }^{27}$ Consistent with prior studies, ${ }^{8} 14$ we observed an inverse relationship between country income group defined by the World Bank and frequency of authorship parasitism, with less developed sub-Saharan African countries experiencing more authorship parasitism. Given the more limited resources available in low-income countries in subSaharan Africa, research conducted in these countries may be more reliant on external support, which in turn may result in higher rates of authorship parasitism as a consequence. Our observation that authorship parasitism was less common in upper-middle income countries in sub-Saharan Africa such as South Africa and Nigeria, implies that economic development in such countries may lead to greater local investigator involvement, and subsequently less authorship parasitism.

The USA, UK and Canada were the HICs most frequently implicated in authorship parasitism. These countries were also commonly involved in articles with authorship parasitism in a study by Hedt-Gauthier et al evaluating articles published from 2014 to 2016 and a study by Dahdouh-Guebas et al that included articles published between 1999 and $2000,{ }^{17}$ suggesting that little has changed in terms of which HICs are commonly implicated in authorship parasitism, even though the relative frequency of authorship parasitism decreased dramatically, from $70 \%$ in $1999-2000^{17}$ to $14.8 \%$ in 2014-2018. However, it should be noted that our use of PubMed, a US-based search engine, could have resulted in over-representation of research with authors affiliated with the USA. Furthermore, the USA alone accounts for $\sim 30 \%$ of all published articles, and the US National Institutes of Health is the leading governmental source of funding in the world. ${ }^{28}{ }^{29}$ Future studies employing different article search engines may elucidate if selection bias results from the use of PubMed.

Our study extends the findings of Hedt-Gauthier et al and Dahdouh-Guebas et al in two important ways. ${ }^{14} 17$ First, we included articles published during a contemporary, 5-year study period. Second, although similar to Hedt-Gauthier et al, we used PubMed to obtain articles, our study adds to prior findings by elucidating journal region, article language, funding source and authorship number patterns associated with authorship parasitism in articles reporting research conducted in sub-Saharan Africa. Articles exhibiting authorship parasitism were more common in journals based in nonsub-Saharan African countries, implying that either those local investigators were more likely to submit their work to journals based in sub-Saharan Africa or that non-sub-Saharan African based journals were more likely to publish work devoid of local authorship representation. Additionally, open-access publication fees in non-sub-Saharan African journals may be a barrier for investigators in sub-Saharan Africa to submit to such journals. Furthermore, articles published in French were less likely to exhibit authorship parasitism, which may suggest Francophone investigators in Francophone sub-Saharan African countries may more commonly submit their work to journals in French than work involving investigators from HICs, particularly those that are English speaking. Moreover, English language standards of journals may create barriers for authors for whom English is not their first language in sub-Saharan Africa for submission to journals published in English. 
Articles reporting private foundation funding were less likely to exhibit authorship parasitism, perhaps suggesting more willingness of private foundations to directly award grants to investigators in LMICs. Furthermore, articles with $>10$ authors were the least likely to have authorship parasitism. Though our study was not designed to assess for this, a lower prevalence of authorship parasitism in articles with expanded authorship bylines may be a manifestation of 'token authorship', which has been commonly reported in work conducted in LMICs, particularly sub-Saharan Africa. ${ }^{30-33}$ Lastly, studies reporting research conducted in more than one sub-Saharan African country commonly exhibited authorship parasitism, which may reflect the dissipation of responsibility in reporting contributions from investigators at each site.

Though authorship dictates academic advancement, the award of future grants and denotes overall contributions of investigators to published work, ${ }^{30} 34$ elucidating disparities in authorship in work reporting research in sub-Saharan Africa is only the 'tip of the iceberg' in understanding power imbalances in global health. ${ }^{23}$ Historical colonialism and neocolonialism, ${ }^{35}$ unequal access to research funds ${ }^{34}$ and capacity building in LMICs focused on transfer of technical skills instead of expertise on study design and manuscript writing ${ }^{23}$ may perpetuate historical imbalances in global health. There has been a recent increase in interest in both studying and implementing more equitable global health partnerships. ${ }^{3637}$ The long-term benefits of such endeavours may provide frameworks that can be replicated and may reduce authorship parasitism over time. Lastly, given the recent surge in interest in decolonising global health, ${ }^{10}$ future studies are merited to assess the impact of this movement on authorship parasitism over time.

There are several areas in need of re-evaluation in order to reduce authorship parasitism in sub-Saharan Africa. First, investigators from HICs conducting research in subSaharan Africa should recognise authorship parasitism as neocolonialist, damaging to partners, and extractive and commit not to engage in such work. Instead, HIC investigators working in sub-Saharan Africa should strive to build research capacity, including providing opportunities for colleagues in sub-Saharan Africa to make meaningful contributions for authorship. Second, HIC institutions should place more value on research when a collaborator from sub-Saharan Africa is in the first or senior author position and raise questions about publications reporting work conducted in sub-Saharan Africa without authors from the region. ${ }^{2}$ Third, funding agencies may consider implementing policies, similar to what has been done with the reporting of race and ethnicity, ${ }^{38}$ requiring balanced contributions leading to authorship in articles reporting federally-funded research conducted in sub-Saharan Africa. Fourth, both reviewers and editors of biomedical journals should recognise this extractive practice and discourage the publication of articles demonstrating authorship parasitism. Fifth, investigators who were not part of the original study design or implementation in sub-Saharan Africa but seek to use data for publications should receive clearance from site directors in the study country(ies). This may be accomplished using data transfer agreements in which all data belong to the study site and foreign collaborators are granted permission to use data by study site investigators. Sixth, given the relatively common occurrence of authorship parasitism in our study, more journals may consider adopting policies requiring authorship from study country authors. ${ }^{3940}$ Lastly, the ICMJE may consider adding recommendations specific to collaborative research conducted in resource-limited settings to encourage equitable opportunities for authorship.

\section{Limitations}

Author affiliation listed in published articles was used to determine an author's country but may not reflect actual country of origin given potential expatriation. However, prior survey studies assessing authorship and perceptions of academic global health collaborations indicate that listed author affiliation strongly correlated with country of origin. ${ }^{3041}$ We were not be able to determine if authorship was inappropriately assigned based on ICMJE standards, if 'token authorship' was granted to investigators, or if investigators were omitted from authorship, which are commonly reported in research conducted in LMICs. ${ }^{30-33}$ Though PubMed includes many journals, it may not include all journal articles that published on research conducted in sub-Saharan Africa during the study period. Particularly, as the NCBI is funded by the US government, our results may reflect an over-representation of journals from the USA. However, given the large sample size of journals based in multiple regions resulting from the query, our sample is broadly representative of research conducted in sub-Saharan Africa. Lastly, not all articles listed funding sources in PubMed which may have introduced some potential overestimation or underestimation of the potential role of funding in published articles demonstrating authorship parasitism. Nevertheless, given our large and representative sample size, it would stand to reason that similar trends would be observed in articles reporting funding elsewhere.

\section{CONCLUSIONS}

Authorship parasitism in studies conducted in subSaharan Africa occurred in approximately one in seven articles. Several high-income countries were most commonly involved in such work conducted in subSaharan Africa. With recent and growing recognition of the perils of imbalanced research collaborations, future studies are merited to evaluate changes in the prevalence, location and associated factors in authorship parasitism in the future. Investigators and institutions in highincome countries, as well as funding agencies and journals should promote research from sub-Saharan Africa, including its publication, in a collaborative and equitable manner. 


\section{Author affiliations}

${ }^{1}$ Department of Pediatrics, Emory University School of Medicine, Atlanta, Georgia, USA

${ }^{2}$ Division of Emergency Medicine, Children's Healthcare of Atlanta, Atlanta, Georgia, USA

${ }^{3}$ Divison of Infectious Diseases, Department of Paediatrics, The Hospital for Sick Children, Toronto, Ontario, Canada

${ }^{4}$ Department of Pediatrics and Child Health, Muhimbili University of Health and Allied Sciences, Dar es Salaam, Tanzania

${ }^{5}$ Department of Pediatrics, John F. Kennedy Medical Center, Monrovia, Liberia ${ }^{6}$ Department of Medicine, Weill Cornell Medicine, New York, New York, USA

${ }^{7}$ Boston Combined Residency Program, Boston, Massachusetts, USA

${ }^{8}$ Baylor Children's Foundation-Malawi, Lilongwe, Malawi

${ }^{9}$ Division of Emergency Medicine, Boston Children's Hospital, Boston,

Massachusetts, USA

${ }^{10}$ Department of Pediatrics and Emergency Medicine, Harvard Medical School, Boston, Massachusetts, USA

${ }^{11}$ Center for Nutrition, Division of Gastroenterology, Hepatology, and Nutrition, Boston Children's Hospital, Boston, Massachusetts, USA

${ }^{12}$ Departments of Nutrition and Global Health and Population, Harvard TH Chan School of Public Health, Boston, Massachusetts, USA

Twitter Mohsin Ali @mohsinali90

Acknowledgements We would like to thank Dr Imikomobong ('Micky') Ibia for his assistance with the query design. We also express our appreciation for the personnel at National Center for Biotechnology Information tools who assisted with the data query.

Contributors CAR, MA, RK, RCI, SJS, CDB, PNK, MN, CD and KM conceptualised and designed the study. CAR, MA and SJS oversaw data collection and verified the underlying data. MA designed the algorithms. MA and $C D B$ verified the underlying data and conducted the statistical analyses. CAR wrote the first draft of the manuscript. CAR, MA, RK, RCI, SJS, CDB, PNK, MN, CD and KM interpreted the data, reviewed and provided input to the final draft. CAR had final responsibility for the decision to submit for publication.

Funding CPD was supported, in part, by the National Institutes of Health (K24 DK104676 and P30 DK040561). The funders had no role in the study design or in the collection, analysis, or interpretation of the data. The funders did not write the report and had no role in the decision to submit the paper for publication.

Map disclaimer The depiction of boundaries on this map does not imply the expression of any opinion whatsoever on the part of BMJ (or any member of its group) concerning the legal status of any country, territory, jurisdiction or area or of its authorities. This map is provided without any warranty of any kind, either express or implied.

\section{Competing interests None declared.}

Patient consent for publication Not applicable.

Ethics approval As this study involved no human subjects and used publicly available data, the Institutional Review Board of Boston Children's Hospital exempted this study from review.

Provenance and peer review Not commissioned; externally peer reviewed.

Data availability statement Data may be made available upon reasonable request to the corresponding author.

Supplemental material This content has been supplied by the author(s). It has not been vetted by BMJ Publishing Group Limited (BMJ) and may not have been peer-reviewed. Any opinions or recommendations discussed are solely those of the author(s) and are not endorsed by BMJ. BMJ disclaims all liability and responsibility arising from any reliance placed on the content. Where the content includes any translated material, BMJ does not warrant the accuracy and reliability of the translations (including but not limited to local regulations, clinical guidelines, terminology, drug names and drug dosages), and is not responsible for any error and/or omissions arising from translation and adaptation or otherwise.

Open access This is an open access article distributed in accordance with the Creative Commons Attribution Non Commercial (CC BY-NC 4.0) license, which permits others to distribute, remix, adapt, build upon this work non-commercially, and license their derivative works on different terms, provided the original work is properly cited, appropriate credit is given, any changes made indicated, and the use is non-commercial. See: http://creativecommons.org/licenses/by-nc/4.0/.

\section{REFERENCES}

1 Koplan JP, Bond TC, Merson MH, et al. Towards a common definition of global health. Lancet 2009;373:1993-5.

2 Hedt-Gauthier B, Airhihenbuwa CO, Bawah AA, et al. Academic promotion policies and equity in global health collaborations. Lancet 2018;392:1607-9.

3 Walsh A, Brugha R, Byrne E. "The way the country has been carved up by researchers": ethics and power in north-south public health research. Int J Equity Health 2016;15:204.

4 Jacobsen $\mathrm{KH}$. Patterns of co-authorship in international epidemiology. J Epidemiol Community Health 2009;63:665-9.

5 Aluede EE, Phillips J, Bleyer J, et al. Representation of developing countries in orthopaedic journals: a survey of four influential orthopaedic journals. Clin Orthop Relat Res 2012;470:2313-8.

6 Pastrana T, Vallath N, Mastrojohn J, et al. Disparities in the contribution of low- and middle-income countries to palliative care research. J Pain Symptom Manage 2010;39:54-68.

7 Chersich MF, Blaauw D, Dumbaugh M, et al. Local and foreign authorship of maternal health interventional research in low- and middle-income countries: systematic mapping of publications 2000 2012. Global Health 2016;12:35.

8 Rees CA, Lukolyo H, Keating EM, et al. Authorship in paediatric research conducted in low- and middle-income countries: parity or parasitism? Trop Med Int Health 2017;22:1362-70.

9 lyer AR. Authorship trends in the Lancet global health. Lancet Glob Health 2018;6:e142.

10 Büyüm AM, Kenney $C$, Koris $A$. Decolonising global health: if not now when? BMJ Glob Heal 2020;5:1-4.

11 Abimbola $S$. The foreign gaze: authorship in academic global health. BMJ Glob Health 2019;4:e002068.

12 et alZaman M, Afridi G, Ohly H. Equitable partnerships in global health research. nature food, 2020. Available: https://www.nature. com/articles/s43016-020-00201-9 [Accessed 17 Mar 2021].

13 Abimbola S, Pai M. Will global health survive its decolonisation? Lancet 2020;396:1627-8.

14 Hedt-Gauthier BL, Jeufack HM, Neufeld NH, et al. Stuck in the middle: a systematic review of authorship in collaborative health research in Africa, 2014-2016. BMJ Glob Health 2019;4:e001853.

15 Siriwardhana C. Promotion and reporting of research from resourcelimited settings. Infect Dis 2015;8:25-29.

16 International Committee of Medical Journal Editors. Recommendations for the conduct, reporting, editing, and publication of scholarly work in medical journals, 2019. Available: http://www.icmje.org/icmje-recommendations.pdf [Accessed 10 Jun 2021].

17 Dahdouh-Guebas F, Ahimbisibwe J, Van Moll R, et al. Neocolonial science by the most industrialised upon the least developed countries in peer-reviewed publishing. Scientometrics 2003:56:329-43.

18 The World Bank. Sub-Saharan Africa, 2019. Available: https:// data.worldbank.org/region/sub-saharan-africa [Accessed April 18, 2019].].

19 National library of medicine. MEDLINE $® P u b M e d \circledast X M L$ element descriptions and their attributes. available. Available: https://www. $\mathrm{nlm}$.nih.gov/bsd/licensee/elements_descriptions.html [Accessed 10 Mar 2020].

20 Gibbs WW. Lost science in the third world. scientific American, 1995. Available: https://www.scientificamerican.com/article/lostscience-in-the-third-world/ [Accessed 16 Mar 2021]

21 Bhaumik S, Jagnoor J. Diversity in the editorial boards of global health journals. BMJ Glob Health 2019;4:2-5.

22 Global health 2021: who tells the story? Lancet Glob Health 2021;9:e99

23 Chaccour J. Authorship trends in the Lancet global health: only the tip of the iceberg? Lancet Glob Health 2018;6:e497.

24 Dimitris MC, Gittings M, King NB. How global is global health research? A large-scale analysis of trends in authorship. BMJ Glob Heal 2021;6:1-7.

25 Mbaye R, Gebeyehu R, Hossmann S, et al. Who is telling the story? A systematic review of authorship for infectious disease research conducted in Africa, 1980-2016. BMJ Glob Health 2019;4:e001855.

26 KFF. U.S. global health budget: overview, 2020. Available: https:// files.kff.org/attachment/Fact-Sheet-US-Global-Health-BudgetOverview.pdf [Accessed 28 Apr 2021].

27 World Bank. Country and lending groups. Available: https:// datahelpdesk.worldbank.org/knowledgebase/articles/906519 [Accessed 10 Jan 2020].

28 Xu Q, Boggio A, Ballabeni A. Countries' Biomedical Publications and Attraction Scores. F1000Res 2014;3:292.

29 Flores G, Lesley B. Children and U.S. federal policy on health and health care: seen but not heard. JAMA Pediatr 2014;168:1155-63. 
30 Rees CA, Keating EM, Dearden KA, et al. Importance of authorship and inappropriate authorship assignment in paediatric research in low- and middle-income countries. Trop Med Int Health 2019;24:1229-42.

31 Kelaher M, Ng L, Knight K, et al. Equity in global health research in the new millennium: trends in first-authorship for randomized controlled trials among low- and middle-income country researchers 1990-2013. Int J Epidemiol 2016;45:2174-83.

32 Adedokun BO, Olopade CO, Olopade OI. Building local capacity for genomics research in Africa: recommendations from analysis of publications in sub-Saharan Africa from 2004 to 2013. Glob Health Action 2016;9:31026.

33 Chu KM, Jayaraman S, Kyamanywa $P$, et al. Building research capacity in Africa: equity and global health collaborations. PLoS Med 2014;11:e1001612.

34 Smith E, Hunt M, Master Z. Authorship ethics in global health research partnerships between researchers from low or middle income countries and high income countries. BMC Med Ethics 2014;15:42.

35 Boshoff N. Neo-colonialism and research collaboration in Central Africa. Scientometrics 2009;81:413-34.
36 UK Collaborative on Development Research. Equitable partnerships resource hub, 2021. Available: https://www.ukcdr.org.uk/guidance/ equitable-partnerships-hub/ [Accessed 28 Apr 2021].

37 Kilmarx PH, Maitin T, Adam T, et al. A mechanism for reviewing investments in health research capacity strengthening in low- and middle-income countries. Ann Glob Health 2020;86:1-4.

38 National Institutes of Health. Nih policy on reporting race and ethnicity data: subjects in clinical research, 2001. Available: https:// grants.nih.gov/grants/guide/notice-files/not-od-01-053.html. [Accessed 06 Nov 2020].

39 Tropical medicine and international health. author guidelines, 2021. Available: https://onlinelibrary.wiley.com/page/journal/13653156/ homepage/forauthors.html [Accessed 28 Apr 2021].

40 Olusanya BO, Mallewa M, Ogbo FA. Beyond pledges: academic journals in high-income countries can do more to decolonise global health. BMJ Glob Health 2021;6:e006200.

41 Rees CA, Keating EM, Dearden KA, et al. Improving pediatric academic global health Collaborative research and agenda setting: a mixed-methods study. Am J Trop Med Hyg 2020;102:649-57. 